\title{
Effect of dehydroepiandrosterone treatment on hormone levels and antioxidant parameters in aged rats
}

\author{
F.J. Yin, J. Kang, N.N. Han and H.T. Ma \\ Key Laboratory of Animal Physiology \& Biochemistry, \\ College of Veterinary Medicine, Nanjing Agricultural University, \\ Nanjing, Jiangsu, China \\ Corresponding author: H.T. Ma \\ E-mail: mahaitian@njau.edu.cn
}

Genet. Mol. Res. 14 (3): 11300-11311 (2015)

Received March 13, 2015

Accepted June 18, 2015

Published September 22, 2015

DOI http://dx.doi.org/10.4238/2015.September.22.24

\begin{abstract}
The aim of the current study was to evaluate the effect of chronic dehydroepiandrosterone (DHEA) administration on steroid hormones and antioxidant parameters in aged rats. To this end, three groups of Sprague-Dawley rats were compared: young (3 months of age) untreated; aged (19 months old) untreated; and aged rats treated with $20 \mathrm{mg} / \mathrm{kg}$ DHEA for 8 weeks. Major organs of aged rats in the untreated group demonstrated physiological atrophy, compared to those of young rats; this effect appeared to have been partially reversed by DHEA treatment. Testosterone and estradiol contents were significantly decreased and aldosterone significantly increased in aged untreated, compared to young untreated rats. Steroid hormone levels were obviously reversed, however, in aged rats treated with DHEA. Additionally, superoxide dismutase activity in serum, brain, heart, and liver was decreased, and maleic dialdehyde content in heart was markedly increased in untreated aged, compared to young, rats. Importantly, these changes in brain and heart of aged rats were reversed by DHEA treatment. Heme oxygenase mRNA levels were increased
\end{abstract}


and inducible nitric oxide synthase mRNA levels decreased in aged, compared to young, rats; DHEA treatment appeared to reverse these changes. These results indicate that chronic DHEA administration may have effects on steroid hormone levels and antioxidant parameters in aged rats and result in postponement of the aging process.

Key words: Dehydroepiandrosterone; Hormone; Antioxidant; Aged rats

\section{INTRODUCTION}

Dehydroepiandrosterone (DHEA) is major steroid hormone produced by the adrenal zona reticularis. One of its main characteristics is aged-dependent pattern secretion; production begins during fetal life and then steadily declines at a rate of 2 to $5 \%$ per year to a total decline of up to $80 \%$ in old age (Genazzani et al., 2007). Clinically, a number of beneficial effects of DHEA treatment have been described and include improved mood states in the clinically depressed (Wolkowitz et al., 1997); improved psychological well-being in the elderly (Morales et al., 1998); and correction of hormone levels in patients with adrenal deficiencies (Hunt et al., 2000). Administration of large doses of DHEA to rodents has demonstrated a multitude of beneficial effects including reduced incidence of cancer, heart disease, diabetes, and obesity (Bacsi et al., 2007). Its availability as a food supplement in the USA has resulted in large-scale self-administration of DHEA as an "anti-ageing" drug, in the absence of medical supervision.

In aging individuals, endocrine changes result in decreased hormone secretion by peripheral glands (Chahal and Drake, 2007). DHEA appears to serve as a prohormone, and could be rapidly metabolized within target tissues into biologically active steroids, including androstenedione, testosterone, and estradiol (Morales et al., 1998; Arlt et al., 1999; Labrie et al., 2007), and, in aged adults, dietary supplementation with DHEA may have protective effects on the brain and heart (Arlt, 2004). Morales et al. (1998) assessed the effect of a large dose (100 mg) of DHEA for a prolonged duration (6 months), on circulating sex steroids in age-advanced men and women, and demonstrated that testosterone was increased to levels above young adult ranges. We have previously demonstrated that serum concentrations of testosterone, estradiol and aldosterone were markedly increased in testis tissues of rats following treatment with DHEA (Song et al., 2010). Androstenedione and testosterone levels have also been shown to be significantly increased in aged adults, following treatment with DHEA (Morales et al., 1998; Labrie et al., 2007). Taken together, these findings suggest that the restoration of DHEA might alter hormone contents, and potentially have anti-ageing effects.

Aging is the progressive deterioration of physiological function and metabolic processes. It has been widely postulated that accumulation of oxidative damage is a causal factor in the aging process (Agarwal and Sohal, 1994). Previous studies have demonstrated ameliorative effects of DHEA against oxidative imbalance, and this has been proposed as the key mechanism for its beneficial effects (Khalil et al., 2000). DHEA supplementation in rodents had antioxidant effects in various acute and chronic oxidative stress protocols (Aragno et al., 2001). Since DHEA secretion exhibits an age-associated pattern, we hypothesized that DHEA may be associated with alterations in steroid hormone levels and in the antioxidant parameters, and that this may result in postponement of the aging process in rats. The primary 
aim of the current study, therefore, was to evaluate the effect of chronic DHEA administration on gonadal hormone levels and antioxidant parameters in young and aged rats, and verify whether changes were associated with postponement of aging in DHEA-treated rats.

\section{MATERIAL AND METHODS}

\section{DHEA}

DHEA was dissolved in dimethylsulfoxide (both Sigma, St. Louis, MO, USA), at 20 $\mathrm{mg} / \mathrm{mL}$ and stored at $-20^{\circ} \mathrm{C}$ until diluted for further use at the dose rate given below.

\section{Animals and experimental design}

Male Sprague-Dawley rats aged three months were obtained from the Shanghai Experimental Animal Center of the Chinese Academy of Sciences (Shanghai, China). Animals were housed in individual cages under conditions of constant temperature $\left(25^{\circ} \mathrm{C}\right)$ and humidity (50\%) and maintained on a 12:12-h light:dark cycle. Animals were given ad libitum access to standard rodent commercial feed and water. All animal handling procedures were performed in strict accordance with guidelines established by the Institutional Animal Care and Use Committee of Nanjing Agricultural University.

For the young (aged 3 months) untreated group (YC), six rats were acclimatized to the environmental conditions described above for 1 week, and were euthanized by decapitation. Remaining rats were kept until the age of 19 months, at which point, 12 rats were randomly assigned to one of two groups (both $\mathrm{N}=6$ ): aged (old) control $(\mathrm{OC})$ and aged DHEA-treated (O-DHEA) groups. For these groups, $20 \mathrm{mg} / \mathrm{kg}$ bodyweight DHEA (O-DHEA rats) or vehicle (OC rats) was administrated by gavage once daily for 8 weeks, at which point, rats were euthanized as for the young control group. At euthanasia, blood samples were collected and testis, liver, heart, and brain tissues were snap frozen in liquid nitrogen and stored at $-70^{\circ} \mathrm{C}$ until further analysis.

\section{Measurement of antioxidant parameters}

Heart and brain samples (approximately $100 \mathrm{mg}$ ) were homogenized on ice with 1 $\mathrm{mL}$ physiological saline in an Ultra-Turrax homogenizer (Staufen, Germany). Homogenate was centrifuged at $3000 \mathrm{~g}$ for $10 \mathrm{~min}$ at $4^{\circ} \mathrm{C}$. Supernatant was frozen for later use in enzyme activity assays. Serum and supernatant superoxide dismutase (SOD) activity and maleic dialdehyde (MDA) content were determined using commercial assay kits (Nanjing Jianchen Biotechnology Institution, Nanjing, China).

\section{Radioimmunoassay (RIA) detection of hormone content}

Blood samples were allowed to clot at $4^{\circ} \mathrm{C}$, centrifuged at $1520 \mathrm{~g}$ for $20 \mathrm{~min}$, and then serum harvested and stored at $-20^{\circ} \mathrm{C}$ until further analysis. Plasma testosterone, estradiol, and aldosterone concentrations were determined using commercial RIA kits according to the manufacturer instructions (Beifang Biotechnology Institution, Beijing, China). 


\section{Real-time quantitative PCR}

Total RNA was extracted from the myocardium samples using TRIZOL reagent (TaKaRa, Shiga, Japan) and an extraction kit according to the manufacturer protocol (Invitrogen, Carlsbad, CA, USA). The RNA concentration was determined by measuring absorbance at $260 \mathrm{~nm}$ in a photometer (Eppendorf Biophotometer). Absorption ratios (260/280 $\mathrm{nm}$ ) for all preparations were between 1.8 and 2.0. Aliquots of RNA samples were subjected to electrophoresis through a $1.4 \%$ agarose/formaldehyde $(\mathrm{w} / \mathrm{v})$ gel to verify RNA integrity.

Reverse transcription (RT) was performed using RNA $(2 \mu \mathrm{g})$ described above in a final volume of $25 \mu \mathrm{L}$, containing $10 \mathrm{U}$ M-MLV reverse transcriptase; $1 \mathrm{mmol}$ dNTP mixture; $40 \mathrm{U}$ recombinant RNase inhibitor; $20 \mu \mathrm{M}$ random primers; and $3 \mathrm{mM} \mathrm{MgCl}$ in sterilized water and buffer (Promega, Madison, WI, USA). Following incubation at $37^{\circ} \mathrm{C}$ for $60 \mathrm{~min}$, the mixture was heat treated at $95^{\circ} \mathrm{C}$ for $5 \mathrm{~min}$ and then quickly cooled on ice. An aliquot of cDNA sample was mixed with $25 \mu \mathrm{L}$ SYBR Green PCR Master Mix (TaKaRa), with 10 pmol of each forward and reverse primer for glutaredoxin (Grx), heme oxygenase-1 (HO-1), and inducible nitric oxide synthase (iNOS) (Table 1), and then subjected to PCR under standard conditions (45 cycles). As an internal control, the same RT products were also subjected to PCR in the presence of a second pair of primers specific to rat $18 \mathrm{~S}$ ribosomal RNA. Mixtures were incubated in an ABI Prism 7300 Sequence Detection System (Applied Biosystems) programmed to conduct one cycle $\left(95^{\circ} \mathrm{C}\right.$ for $\left.5 \mathrm{~min}\right)$ and 40 cycles $\left(95^{\circ} \mathrm{C}\right.$ for $20 \mathrm{~s}, 62^{\circ} \mathrm{C}$ for $30 \mathrm{~s}$, and $72^{\circ} \mathrm{C}$ for $30 \mathrm{~s}$ ). Results (fold changes) were expressed as $2^{-\Delta \Delta \mathrm{Ct}}$ with $\Delta \Delta \mathrm{Ct}=\left(\mathrm{Ct}_{\mathrm{ij}}-\mathrm{Ct}\right.$ $\beta$-actin $\left.{ }_{\mathrm{j}}\right)-\left(\mathrm{Ct}_{\mathrm{i} 1}-\mathrm{Ct} \beta\right.$-actin $\left._{1}\right)$, where $C t_{i j}$ and $C t \beta$ - actin $_{j}$ are the $\mathrm{Ct}$ for gene $\mathrm{i}$ and for $\beta$-actin in a pool or a sample (named $\mathrm{j}$ ) and where $C t_{i l}$ and $C t \beta$-actin ${ }_{l}$ are the $\mathrm{Ct}$ in pool 1 or sample 1, expressed as the standard. The primers used (18S) were determined according to published guidelines (Schmitt et al., 2001) or designed by Primes Premier 5 (iNOS, Grx and HO-1) and synthesized by TaKaRa Biological Company.

\begin{tabular}{|c|c|c|c|c|}
\hline Gene & GenBank accession No. & Primer sequences $\left(5^{\prime}-3^{\prime}\right)$ & Orientation & Product size (bp) \\
\hline GRX & NC_005101.2 & $\begin{array}{l}\text { AGTCTGGAAAGGTGGTCG } \\
\text { ATCGCATTGGTGTTGTTAGT }\end{array}$ & $\begin{array}{l}\text { Forward } \\
\text { Reverse }\end{array}$ & 139 \\
\hline $\mathrm{HO}-1$ & BC_091164.1 & $\begin{array}{l}\text { TTCACCTTCCCGAGCATC } \\
\text { AGCCTCTTCTGTCACCCT }\end{array}$ & $\begin{array}{l}\text { Forward } \\
\text { Reverse }\end{array}$ & 111 \\
\hline iNOS & NM_012611.3 & $\begin{array}{l}\text { GGAGCGAGTTGTGGATTG } \\
\text { AACCTCTGCCTGTGCGTC }\end{array}$ & $\begin{array}{l}\text { Forward } \\
\text { Reverse }\end{array}$ & 213 \\
\hline $18 \mathrm{~S}$ & NR_046237 & $\begin{array}{l}\text { GAAACGGCTACCACATCC } \\
\text { ACCAGACTTGCCCTCCA }\end{array}$ & $\begin{array}{l}\text { Forward } \\
\text { Reverse }\end{array}$ & 167 \\
\hline
\end{tabular}

\section{Statistical analysis}

Body weight data were subjected to one-way analysis of variance (ANOVA) testing. Differences in hormone levels, antioxidant parameters and the mRNA expression among the three groups were compared using one-way ANOVA and the $t$-test for significance followed by pair comparisons. Data are reported as mean \pm SE. Levels of significance for all statistical tests were set at $5 \%$. All statistical analyses were performed using Statistical Packages for Social Science 16.0 (SPSS Inc., USA) and MS (Microsoft) Excel 2003. 


\section{RESULTS}

\section{Impact of DHEA on body weight in aging rats}

Body weights of old rats during the total 8 weeks of experimentation are shown in Figure 1. In the OC group, rats gradually lose weight over the experimental period $(\mathrm{P}>0.05)$; the mean weight for the group began at $624.3 \pm 25.1$ and ended at $606.9 \pm 39.8 \mathrm{~g}$. Body weights for rats in the O-DHEA group decreased for the first three weeks of treatment, then gradually increased from 4 weeks to the experiment end, although a slight decrease was seen in the last week. However, when compared with the OC group, changes O-DHEA group weights were not significant $(\mathrm{P}>0.05)$.

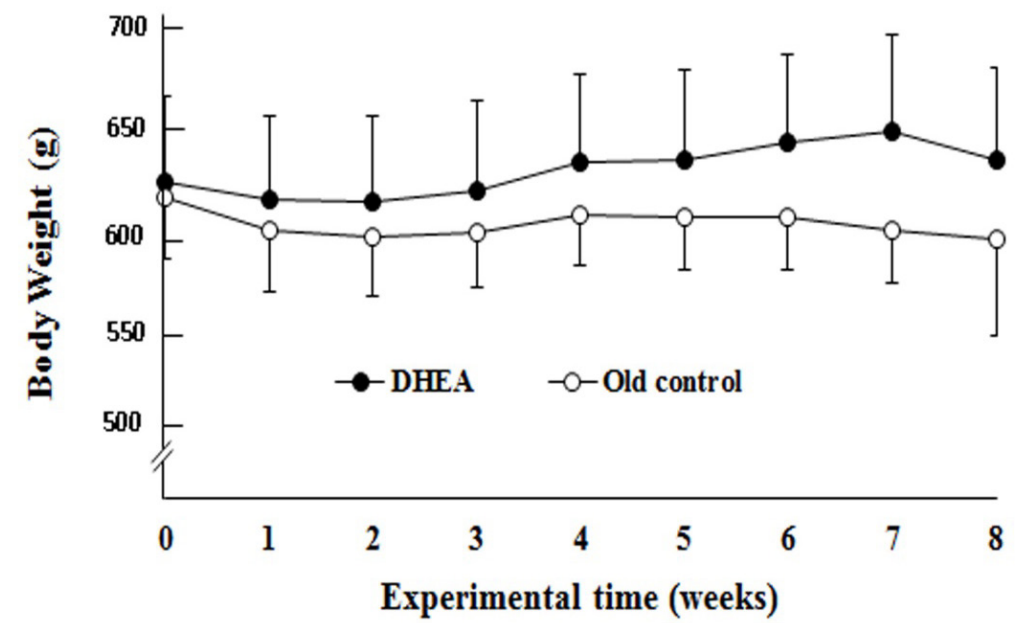

Figure 1. Effect of DHEA on body weight in aging rats. Body weights of rats in the OC group gradually declined over the experimental period. DHEA-treated rats gradually increased from 4 weeks onwards, with a slight decrease in the last week. Differences in body weights between the O-DHEA and OC groups were not significant. Values are reported as means $\pm \mathrm{SE}$.

\section{Effect of DHEA on carcass composition in aging rats}

Ten organs were weighed from each animal; of these, four were found to differ between treatment groups (Table 2). Weights of liver, brain, testis, and epididymis, expressed as a percentage of body weight, were significantly lower for $\mathrm{OC}$ than for YC group rats $(\mathrm{P}<0.01)$. In the O-DHEA group, weights of liver, brain, testis, and epididymis were significant lower than the YC group $(\mathrm{P}<0.01)$, but were comparable to those of rates in the $\mathrm{OC}$ group $(\mathrm{P}>0.05)$.

\section{Effect of DHEA on the content of hormones in aging rats}

Testosterone (Figure 2A) and estradiol (Figure 2B) contents were significantly decreased $(\mathrm{P}<0.05)$, and aldosterone content significantly increased $(\mathrm{P}<0.05)$ in the OC group, compared to the YC group (Figure 2C). It was noted that DHEA-treatment of rats appeared to reverse these alterations of testosterone, estradiol, and aldosterone content. As shown in Figure 2A and B, testosterone and estradiol content were significantly increased in the 
O-DHEA group, compared with the OC group $(\mathrm{P}<0.05)$. Although no significant differences were observed in aldosterone content in aging rats treated with DHEA (Figure 2C) $(\mathrm{P}>0.05)$.

\begin{tabular}{|c|c|c|c|}
\hline Tissue $(\%)^{\dagger}$ & $\mathrm{YC}$ & $\mathrm{OC}$ & O-DHEA \\
\hline Heart & $0.35 \pm 0.01$ & $0.34 \pm 0.03$ & $0.32 \pm 0.02$ \\
\hline Liver & $2.71 \pm 0.054$ & $2.14 \pm 0.086^{* *}$ & $2.35 \pm 0.078 * *$ \\
\hline Brain & $0.56 \pm 0.02$ & $0.348 \pm 0.02 * *$ & $0.33 \pm 0.02 * *$ \\
\hline Lungs & $0.61 \pm 0.04$ & $0.82 \pm 0.13$ & $0.58 \pm 0.05$ \\
\hline Kidney & $0.61 \pm 0.03$ & $0.56 \pm 0.05$ & $0.50 \pm 0.02$ \\
\hline Testis & $1.06 \pm 0.04$ & $0.56 \pm 0.04 * *$ & $0.53 \pm 0.04 * *$ \\
\hline Epididymis & $0.16 \pm 0.01$ & $0.10 \pm 0.01 * *$ & $0.11 \pm 0.01 * *$ \\
\hline Prostate & $0.22 \pm 0.01$ & $0.23 \pm 0.02$ & $0.21 \pm 0.020$ \\
\hline Thymus & $0.11 \pm 0.02$ & $0.08 \pm 0.01$ & $0.11 \pm 0.01$ \\
\hline Spleen & $0.20 \pm 0.01$ & $0.17 \pm 0.01$ & $0.21 \pm 0.03$ \\
\hline
\end{tabular}

Tissue weight as a percentage of body weight. Values are reported as means $\pm \mathrm{SEM} ; \mathrm{N}=6 .{ }^{* *} \mathrm{P}<0.01$, compared with the YC group.
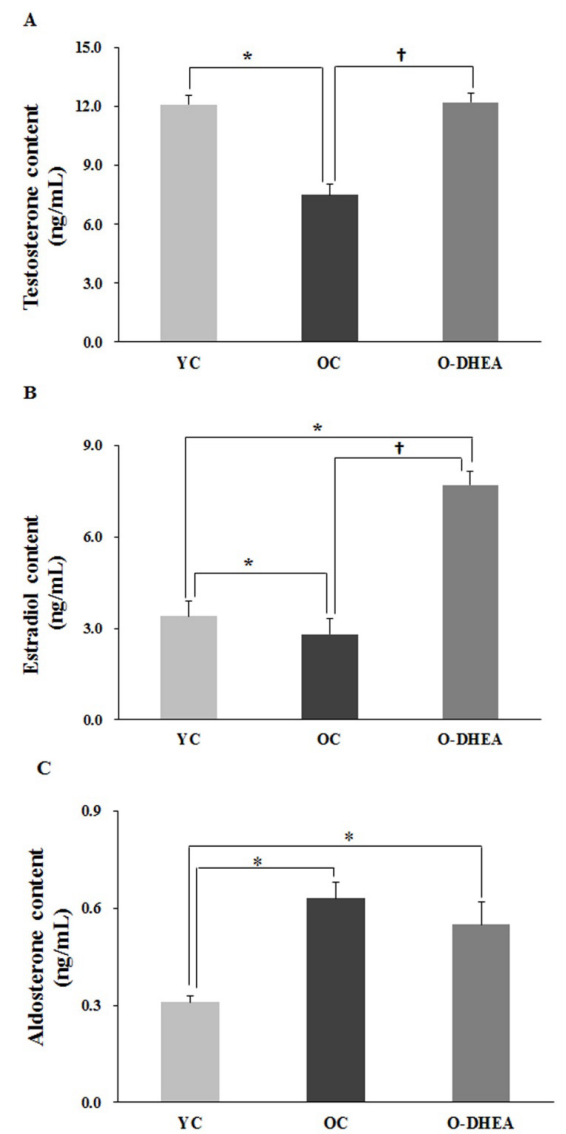

Figure 2. Effect of DHEA on the testosterone (A), estradiol (B), and aldosterone (C) contents in aging rats. Testosterone and estradiol levels were significantly lower in the OC group than the YC group, while aldosterone levels were significantly higher. Testosterone, estradiol and aldosterone levels were reversed in aging rats treated with DHEA. Values are reported as means \pm SE. ${ }^{*} \mathrm{P}<0.05$, compared with the $\mathrm{YC}$; ${ }^{\dagger} \mathrm{P}<0.05$, compared with the OC. 


\section{Effect of DHEA on antioxidant parameters in aging rats}

Superoxide dismutase activity in serum, brain, heart and liver were decreased in the OC group, compared to the $\mathrm{YC}$ group $(\mathrm{P}>0.05$; Figure $3 \mathrm{~A})$. No significantly differences were observed in the O-DHEA group, but SOD activity in brain and heart was increased compared with the OC group $(\mathrm{P}>0.05)$. Maleic dialdehyde content in heart was significantly increased in the OC group, compared to the YC group $(\mathrm{P}<0.05)$, while no significantly difference was observed in serum, brain, and liver $(\mathrm{P}>0.05)$. Similar, MDA content in brain and heart was decreased in the O-DHEA group, compared with the OC group $(\mathrm{P}>0.05$; Figure $3 \mathrm{~B})$.

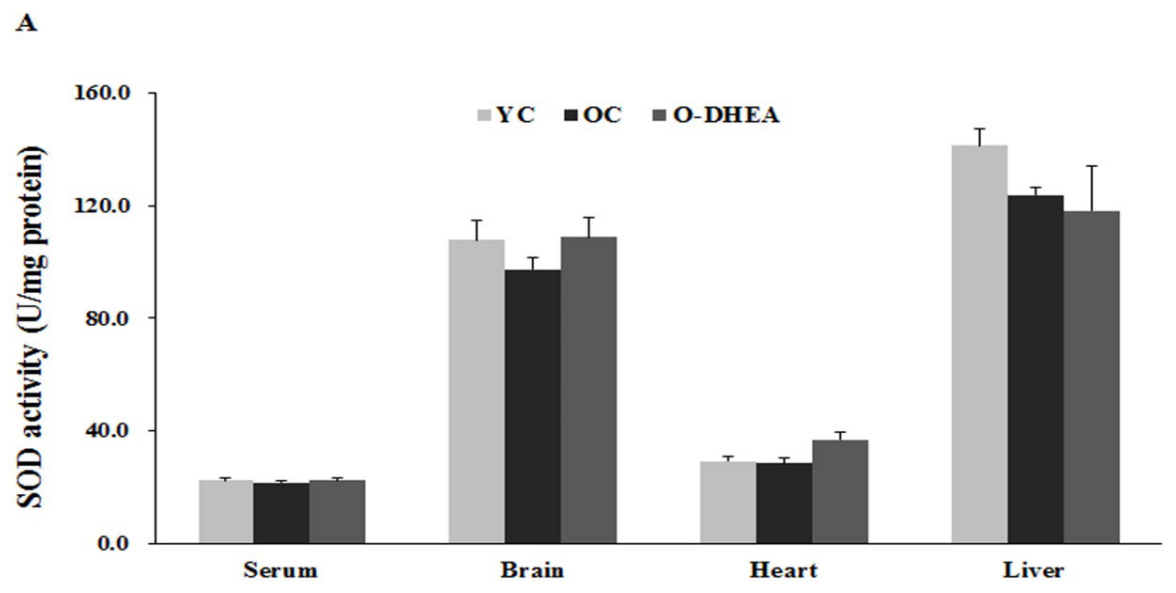

$\mathbf{B}$

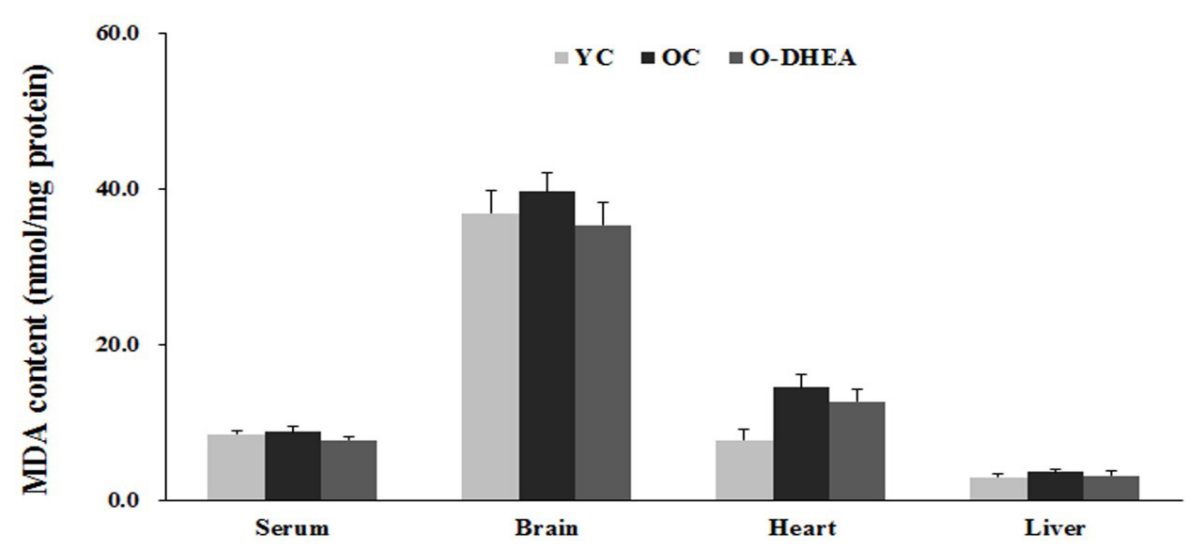

Figure 3. Effect of DHEA on the superoxide dismutase (SOD) activity (A) and maleic dialdehyde (MDA) content (B) in aging rats. SOD activity was decreased in serum, brain, heart and liver of the OC group in comparison to the YC group. No significant differences were observed in the O-DHEA group, but SOD activity, especially in the brain and heart, was partially increased compared with the OC group. MDA content in heart was markedly increased in the OC group compared with the YC group. Similar, MDA contentin brain and heart was partially reduced in the O-DHEA group compared with the OC group. Values are reported as means $\pm \mathrm{SE}$. ${ }^{*} \mathrm{P}<0.05$, compared with the $\mathrm{YC}$. 


\section{Effect of DHEA on gene expression associated with antioxidant in aging rats}

No significant differences were observed in Grx mRNA levels in the OC group, compared with the YC group ( $\mathrm{P}>0.05$; Figure $4 \mathrm{~A})$. Levels of HO-1 mRNA were significantly increased $(\mathrm{P}<0.05$; Figure 4B), whereas iNOS mRNA abundance (Figure 4C) significantly decreased $(\mathrm{P}<0.05)$ in the $\mathrm{OC}$ group, compared with the $\mathrm{YC}$ group. There were no significantly differences in values when O-DHEA and OC groups were compared, although HO-1 mRNA levels showed a trend toward decrease and iNOS mRNA levels showed a trend toward enhancement in the O-DHEA group $(\mathrm{P}>0.05)$.

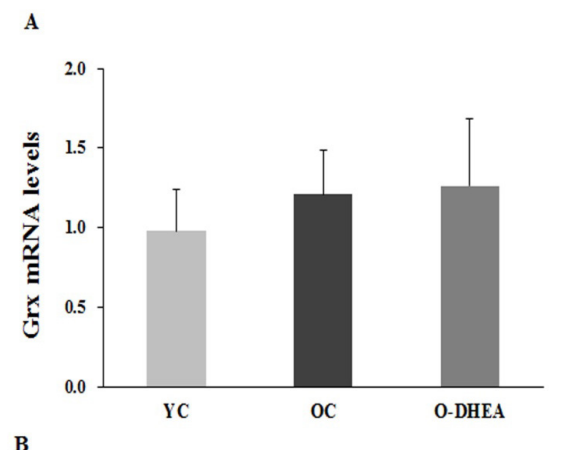

B

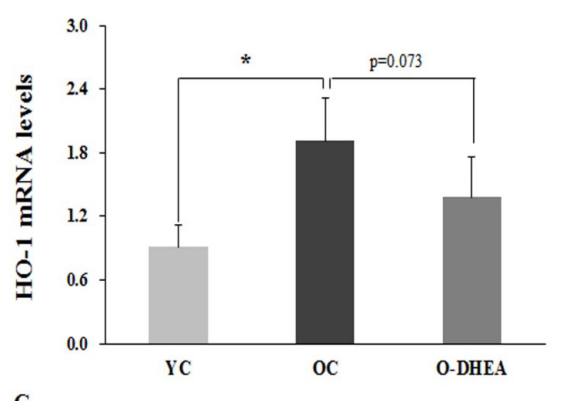

C

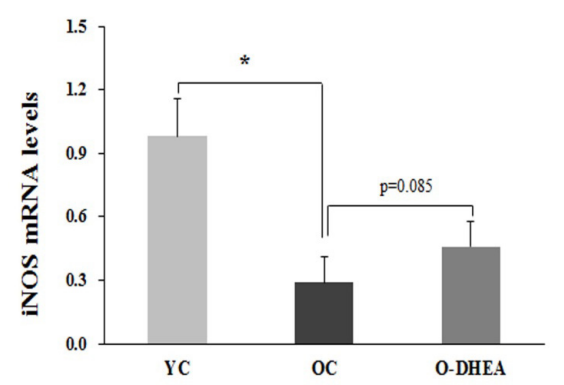

Figure 4. Effect of DHEA on glutaredoxin (Grx) (A), heme oxygenase-1 (HO-1) (B), and nitric oxide synthase (iNOS) (C) mRNA levels in myocardium of aging rats. Grx mRNA expression levels were comparable between the groups. HO-1 mRNA expression was significantly increased and iNOS mRNA expression was decreased in the OC group, in comparison to the YC group. Although not significantly different, HO-1 mRNA expression showed a trend toward partial decrease, and iNOS mRNA expression showed a trend toward enhancement in the O-DHEA group, compared tothe OC group. Values are reported as means $\pm \mathrm{SE}$. ${ }^{*} \mathrm{P}<0.05$, compared with the YC. 


\section{DISCUSSION}

Aging is characterized by the declining function of brain, heart, and liver by various mechanisms, including changes in the synthesis of neurotransmitters, growth factors, and steroids (Smith et al., 2005). In the current study, the relative weights of liver, brain, testis, and epididymis were significantly decreased in aged, compared to young rats, and those changes were reversed in old rats by treatment with DHEA. This result indicates that DHEA-treatment may delay the onset of physiological atrophy in certain major organs of aged rats. Chahal and Drake (2007) confirmed that aging causes oxidation stress, which may lead decreased endocrine function. In our study, we demonstrated that testosterone and estradiol levels were significantly reduced in aged, compared to young rats. Previous studies have shown that decreased testosterone and estradiol levels, as well as reduced gonadal secretion and responsiveness, are associated with increasing age (Walf and Frye, 2005). Notably, in the current study, DHEA treatment appeared to markedly reverse alterations in testosterone and estradiol content, when these parameters were compared between treated and untreated aged rats. This observation is consistent with the findings of Arlt et al. (1999), who demonstrated that serum testosterone and estradiol concentrations were significantly increased in healthy elderly treated with DHEA. A recent study showed that estradiol treatment appears to be beneficial in preventing age-related changes in the brain (Martinez-Mota et al., 2011). In the current study, we showed that serum estradiol concentrations were significantly increased, from $2.81 \mathrm{ng} / \mathrm{mL}$ in the OC group to $7.70 \mathrm{ng} / \mathrm{mL}$ in rats that received DHEA treatment for eight weeks. Labrie et al. (2007) also observed estradiol to be $158 \%$ greater than basal levels, following exogenous DHEA treatment in postmenopausal women. Our study showed that the aldosterone content was significantly increased in aged, compared to young rats. Although no significant differences were observed in aldosterone content in aged rats that received DHEA, we observed a tendency toward decreased levels in these animals, when compared with the OC group. Some research has linked aldosterone to myocardial fibrosis (Weber and Brilla, 1991), direct vascular damage (Rocha et al., 1998), and baroreceptor dysfunction (Wang, 1994) and prevention of norepinephrine uptake by myocardium (Struthers, 1996). We therefore speculate that alterations in aldosterone content are a self-protective mechanism that may alleviate oxidative stress in aged rats. These results suggest that DHEA treatment may restore gonad function in old rats.

It is well known that the oxidation ability is gradually increased and anti-oxidizing ability gradually decreased throughout the aging process in mammals. We observed a reduction in SOD activity, and increased MDA content in the OC group throughout the experimental period. This is consistent with the results of Lei et al. (2008), who reported that serum SOD activity is significantly diminished, and MDA levels pronouncedly increased, in aging model rats. SOD catalyzes the dismutation of the superoxide radical $\left(\mathrm{O}^{2-}\right)$ into hydrogen peroxide $\left(\mathrm{H}_{2} \mathrm{O}_{2}\right)$ and elemental oxygen $\left(\mathrm{O}_{2}\right)$ and as such, provides an important defense against the toxicity of superoxide radical. MDA is one of several by-products of lipid per-oxidation processes. In a previous report, treatment of 18-month-old rats with $1 \mathrm{mg} / \mathrm{kg}$ DHEA for 6 months resulted in increased serum MDA, but reduced serum SOD activity, compared to untreated animals (Wu et al., 2007). In the current study, we observed that for DHEA-treated animals, SOD activity tended to increase, and MDA content to decrease compared to untreated aged controls, particularly in brain and heart, although differences were not statistically 
significant. Additionally, SOD activity and MDA content values in aged DHEA treated rats were comparable to those of the young rat control group. These findings indicate that SOD activity and MDA content may be affected by DHEA treatment only in specific organs in aged rats.

Our data demonstrates alterations of HO-1 and iNOS mRNA levels along with changes in oxidative stress parameters in aged rats. It had reported that heart function atrophy is consistent evidence of aging (Jacob et al., 2010; Fan et al., 2011; Shih et al., 2011). HO-1 is an enzyme that catalyzes heme degradation, resulting in the production of biliverdin, iron, and carbon monoxide (Kikuchi et al., 2005). The enzyme and its decomposition products are induced by oxidative stress, and it acts as an endogenous protective protein in a long series of peripheral target intracrine tissues (Yin et al., 2010). In the present study, HO-1 mRNA levels were significantly increased in the myocardium of aged rats, indicating that aging may induce HO-1 expression in this tissue. Shih et al. (2011) reported that aging results in increased myocardial apoptosis. In another study, HO-1 was up regulated in response to an endogenous antioxidant factor induced by oxidative stress in various cells (Brouard et al., 2000). We observed that HO-1 mRNA levels were reduced in the myocardium of aged rats treated with DHEA. Similarly, we found that iNOS mRNA abundance was significantly decreased in the OC group, but showed a trend toward enhancement in the O-DHEA group compared with the OC group. Previous studies have shown that aging may exacerbate oxidative stress and the risk of cardiovascular disease factors such as impaired mitochondrial function (Madamanchi and Runge, 2007), iNOS uncoupling (Yang et al., 2009) and a decrease in endogenous antioxidant enzyme defenses (Go et al., 2010). Estrogenic and/or hormetic actions of isoflavones reportedly counteract oxidative stress by up-regulating the activity and expression of iNOS (Mann et al., 2009), providing a clinically relevant therapeutic target to prolong health span and reduce the incidence of age-related cardiovascular disease. Thus, we propose that the effect of DHEA on the HO-1 and iNOS mRNA levels in myocardium may be relevant to delaying the aging process, and that the precise mechanism by which this occurs is an important focus for further investigation.

In conclusion, we have demonstrated that chronic DHEA treatment of aged rats resulted in regulation of steroid hormone levels and antioxidant parameters, and a postponement of the aging process. Regardless of the mechanism, these data highlight an important interrelationship between DHEA treatment and the host response to aging; this has significant biological relevance for delaying animal aging and improving old animal production performance. Further studies are warranted to confirm the efficacy of DHEA treatment in prevention of aging, and to better understand the mechanisms underlying the effect of DHEA treatment on aging.

\section{Conflicts of interest}

The authors declare no conflicts of interest.

\section{ACKNOWLEDGMENTS}

Research supported by project funding from the Priority Academic Program Development of Jiangsu Higher Education Institutions (PAPD). 


\section{REFERENCES}

Agarwal S and Sohal RS (1994). Aging and protein oxidative damage. Mech. Ageing Dev. 75: 11-19.

Aragno M, Parola S, Brignardello E, Manti R, et al. (2001). Oxidative stress and eicosanoids in the kidneys of hyperglycemic rats treated with dehydroepiandrosterone. Free Radic. Biol. Med. 31: 935-942.

Arlt W (2004). Dehydroepiandrosterone and ageing. Best Pract. Res. Clin. Endocrinol. Metab. 18: 363-380.

Arlt W, Haas J, Callies F, Reincke M, et al. (1999). Biotransformation of oral dehydroepiandrosterone in elderly men: significant increase in circulating estrogens. J. Clin. Endocrinol. Metab. 84: 2170-2176.

Bacsi K, Kosa J, Lazary A, Horvath H, et al. (2007). Significance of dehydroepiandrosterone and dehydroepiandrosterone sulfate in different diseases. Orv. Hetil. 148: 651-657.

Brouard S, Otterbein L, Anrather J, Tobiasch E, et al. (2000). Carbon monoxide generated by heme oxygenase 1 suppresses endothelial cell apoptosis. J. Exp. Med. 192: 1015-1025.

Chahal HS and Drake WM (2007). The endocrine system and ageing. J. Pathol. 211: 173-180.

Fan Q, Yang XC, Liu Y, Wang LF, et al. (2011). Postconditioning attenuates myocardial injury by reducing nitro-oxidative stress in vivo in rats and in humans. Clin. Sci. 120: 251-261.

Genazzani AD, Lanzoni C and Genazzani AR (2007). Might DHEA be considered a beneficial replacement therapy in the elderly? Drugs Aging 24: 173-185.

Go YM, Park H, Koval M, Orr M, et al. (2010). A key role for mitochondria in endothelial signaling by plasma cysteine/ cystine redox potential. Free Radic. Biol. Med. 48: 275-283.

Hunt PJ, Gurnell EM, Huppert FA, Richards C, et al. (2000). Improvement in mood and fatigue after dehydroepiandrosterone replacement in Addison's disease in a randomized, double blind trial. J. Clin. Endocrinol. Metab. 85: 4650-4656.

Jacob MH, Da R Janner D, Jahn MP, Kucharski LC, et al (2010). Age-related effects of DHEA on peripheral markers of oxidative stress. Cell Biochem. Funct. 28: 52-57.

Khalil A, Fortin JP, LeHoux JG and Fulop T (2000). Age-related decrease of dehydroepiandrosterone concentrations in low density lipoproteins and its role in the susceptibility of low density lipoproteins to lipid peroxidation. J. Lipid Res. 41: 1552-1561.

Kikuchi G, Yoshida T and Noguchi M (2005). Heme oxygenase and heme degradation. Biochem. Biophys. Res. Commun. 338: 558-567.

Labrie F, Belanger A, Belanger P, Berube R, et al. (2007) Metabolism of DHEA in postmenopausal women following percutaneous administration. J. Steroid Biochem. Mol. Biol. 103: 178-188.

Lei M, Hua X, Xiao M, Ding J, et al. (2008). Impairments of astrocytes are involved in the d-galactose-induced brain aging. Biochem. Biophys. Res. Commun. 369: 1082-1087.

Madamanchi NR and Runge MS (2007). Mitochondrial dysfunction in atherosclerosis. Circ. Res. 100: 460-473.

Mann GE, Bonacasa B, Ishii T and Siow RC (2009). Targeting the redox sensitive Nrf2-Keap1 defense pathway in cardiovascular disease: protection afforded by dietary isoflavones. Curr. Opin. Pharmacol. 9: 139-145.

Martinez-Mota L, Ulloa RE, Herrera-Perez J, Chavira R, et al. (2011). Sex and age differences in the impact of the forced swimming test on the levels of steroid hormones. Physiol. Behav. 104: 900-905.

Morales AJ, Haubrich RH, Hwang JY, Asakura H, et al (1998). The effect of six months treatment with a $100 \mathrm{mg}$ daily dose of dehydroepiandrosterone (DHEA) on circulating sex steroids, body composition and muscle strength in ageadvanced men and women. Clin. Endocrinol. 49: 421-432.

Rocha R, Chander PN, Khanna K, Zuckerman A, et al. (1998). Mineralocorticoid blockade reduces vascular injury in stroke-prone hypertensive rats. Hypertension 31: 451-458.

Schmitt M, Klinga K, Schnarr B, Morfin R, et al. (2001). Dehydroepiandrosterone stimulates proliferation and gene expression in MCF-7 cells after conversion to estradiol. Mol. Cell Endocrinol. 173: 1-13.

Shih H, Lee B, Lee RJ and Boyle AJ (2011). The aging heart and post-infarction left ventricular remodeling. J. Am. Coll. Cardiol. 57: 9-17.

Smith RG, Betancourt L and Sun Y (2005). Molecular endocrinology and physiology of the aging central nervous system. Endocr. Rev. 26: 203-250.

Song L, Tang X, Kong Y, Ma H, et al. (2010). The expression of serum steroid sex hormones and steroidogenic enzymes following intraperitoneal administration of dehydroepiandrosterone (DHEA) in male rats. Steroids 75: 213-218.

Struthers AD (1996). Aldosterone escape during angiotensin-converting enzyme inhibitor therapy in chronic heart failure. J. Card. Fail. 2: 47-54.

Walf AA and Frye CA (2005). Antianxiety and antidepressive behavior produced by physiological estradiol regimen may be modulated by hypothalamic-pituitary-adrenal axis activity. Neuropsychopharmacology 30: 1288-1301.

Wang W (1994). Chronic administration of aldosterone depresses baroreceptor reflex function in the dog. Hypertension 24: $571-575$. 
Weber KT and Brilla CG (1991). Pathological hypertrophy and cardiac interstitium. Fibrosis and renin-angiotensinaldosterone system. Circulation 83: 1849-1865.

Wolkowitz OM, Reus VI, Roberts E, Manfredi F, et al. (1997). Dehydroepiandrosterone (DHEA) treatment of depression. Biol. Psychiatry 41: 311-318.

Wu S, Ruan Y, Yin M and Lai W (2007). Research on the age-related changes in the nitric oxide pathway in the arteries of rats and the intervention effect of dehydroepiandrosterone. Gerontology 53: 234-237.

Yang YM, Huang A, Kaley G and Sun D (2009). eNOS uncoupling and endothelial dysfunction in aged vessels. Am. J. Physiol. Heart Circ. Physiol. 297: H1829-H1836.

Yin H, Li X, Gong Q, Jin X, et al. (2010). Heme oxygenase-1 upregulation improves lipopolysaccharide-induced acute lung injury involving suppression of macrophage migration inhibitory factor. Mol. Immunol. 47: 2443-2449. 